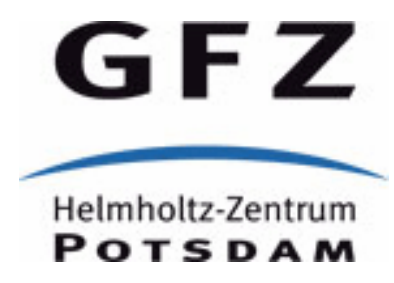

Originally published as:

Heise, S., Wickert, J., Beyerle, G., Schmidt, T., Smit, H., Cammas, J. P., Rothacher, M. (2008): Comparison of Water Vapour and Temperature Results From GPS Radio Occultation Aboard CHAMP With MOZAIC Aircraft Measurements. - IEEE Transactions on Geoscience and Remote Sensing, 46, 11, 3406-3411

DOI: $10.1109 / T G R S .2008 .920268$ 


\title{
Comparison of water vapour and temperature results from GPS radio occultation aboard CHAMP with MOZAIC aircraft measurements
}

\author{
Stefan Heise, Jens Wickert, Georg Beyerle, Torsten Schmidt, Herman Smit, Jean- \\ Pierre Cammas, and Markus Rothacher
}

\begin{abstract}
Global Positioning System (GPS) Radio Occultation (RO) observations aboard Low Earth Orbiting (LEO) satellites provide a powerful tool for global atmospheric sounding. Activated almost continuously since mid-2001, the CHAMP (CHAllenging Minisatellite Payload) GPS RO experiment provides up to 200 vertical atmospheric profiles per day. In this study we intercompare CHAMP RO humidity results and analyses from the European Centre for Medium-Range Weather Forecasts (ECMWF) with coinciding MOZAIC (Measurement of OZone and water vapour by AIrbus in-service airCraft) data collected during aircraft ascents and descents. About 320 coinciding profiles with CHAMP were found from 2001 until 2006 (coincidence radius: 3 hours, $300 \mathrm{~km}$ ). Between about 650 and $300 \mathrm{hPa}$ the CHAMP-MOZAIC humidity bias is smaller than the ECMWFMOZAIC bias. On the other hand, the standard deviation between MOZAIC and CHAMP humidity is slightly higher than between MOZAIC and ECMWF through the entire altitude range. Apart from the water vapour validation (ascent and descent data), we also compare MOZAIC cruise data at typically 10-11 km altitude with CHAMP refractivity and temperature results (dry retrieval) and corresponding ECMWF analysis data. Whereas refractivity data from MOZAIC, CHAMP and ECMWF show excellent agreement, the CHAMP temperature exhibits a cold bias of about $0.9 \mathrm{~K}$ in comparison to MOZAIC and ECMWF.
\end{abstract}

Index Terms-CHAMP, GPS radio occultation, MOZAIC, water vapor, troposphere.

\section{INTRODUCTION}

$\mathbf{T}$ HE Global Positioning System (GPS) Radio Occultation (RO) technique (e.g., [8], [17]) exploits atmospheric refraction of GPS signals observed aboard Low Earth Orbiting (LEO) satellites for remote sensing of the Earth's atmosphere. The atmospheric excess phase along the occultation satellite link is the basic observable which is used to retrieve vertical profiles of refractivity and subsequently meteorological quantities like pressure, temperature and water vapor. GPS RO observations require no calibration, are not affected by clouds, aerosols or precipitation, and provide an almost uniform global coverage. Therefore, the GPS RO technique provides a unique data source for applications in numerical weather prediction (e.g., [4]) and climatological investigations. The CHAMP (CHAllenging Minisatellite Payload, e.g., [12])

S. Heise, J. Wickert, G. Beyerle, T. Schmidt and M. Rothacher are with the Department 1 Geodesy and Remote Sensing, GeoForschungsZentrum Potsdam (GFZ), Telegrafenberg, D-14473, Germany e-mail: stefan.heise @gfzpotsdam.de

H. Smit is with Research Centre Jülich, Germany.

J.-P. Cammas is with CNRS, Laboratoire d' Aerologie, Toulouse, France.

Manuscript received September 1, 2007; revised December 21, 2007.
GPS RO experiment runs almost continuously since mid-2001, providing up to 200 vertical atmospheric profiles per day (e.g., [15]). Thus, CHAMP provides the first long term GPS RO data set; the mission will presumably continue until 2009. Recently launched GPS RO satellite missions (e.g., COSMIC [13] and Metop [10]) dramatically increased the number of daily available GPS RO measurements. The GPS RO refractivity is in good agreement with other meteorological data (e.g., radiosondes or European Centre for Medium-Range Weather Forecasts (ECMWF) analyses) in the upper troposphere and lower stratosphere (e.g., [14]). But in the lower troposphere (in particular in tropical regions) a significant negative bias is observed (e.g., [1]), which also affects the humidity retrieval. Nevertheless, in the mid troposphere region CHAMP humidity results show good agreement with ECMWF and radiosonde data [5]. In this study we intercompare CHAMP RO humidity data and analyses from the ECMWF (used as ancillary data in the humidity retrieval) with coinciding MOZAIC (Measurement of OZone and water vapour by AIrbus in-service airCraft) data collected during aircraft ascents and descents. Currently, the MOZAIC programme includes five aircraft performing up to 2,500 flights per year. Since MOZAIC data are not assimilated to ECMWF analyses, this comparison provides an opportunity to assess whether GPS RO data could provide significant additional water vapour information in comparison to ECMWF. Apart from the water vapour validation (ascent and descent data) we also compare CHAMP refractivity and temperature results (dry retrieval) with MOZAIC cruise data at typically $10-11 \mathrm{~km}$ altitude.

\section{DATA ANALYSIS}

\section{A. GPS data}

There are several publications describing the GPS RO technique for retrieval of vertical atmospheric profiles in detail (e.g., [11], [8], [17]). At GFZ Potsdam, the CHAMP GPS RO retrieval results are generated by an operational occultation analysis system [14]. Together with the GFZ RO infrastructure (including a polar receiving station) this processing system allows for provision of atmospheric profiles on average about 1.5 hours after the occultation measurement [16]. Vertical profiles of refractivity are derived from atmospheric excess phase using the wave optics approach and the Abel inversion technique (e.g., [2]). The Full Spectrum Inversion (FSI) technique [7] is used for the retrieval in the lower troposphere. GFZs RO 
analysis results (Level 3 data, atmospheric profiles, current version 005) are provided via CHAMPs ISDC (Information System and Data Center): http://isdc.gfz-potsdam.de. More details on the operational data analysis and the quality of the data products are given by [14]. Since the atmospheric refractivity $N$ (Eq. 1) is related to air pressure ( $p$ ), air temperature $(T)$ and water vapor pressure $\left(p_{w}\right)$, vertical profiles of the tropospheric humidity can only be derived using ancillary atmospheric information from, e.g., meteorological analyses. At GFZ two different water vapour retrieval algorithms are implemented for operational processing: The 1DVAR retrieval according to [3], and the DWVP retrieval (Direct Water Vapour Pressure; [5]). Ancillary data for humidity retrieval are generally extracted from global ECMWF analyses.

$$
N=77.6 \frac{p}{T}+3.73 \cdot 10^{5} \frac{p_{w}}{T^{2}}
$$

\section{B. MOZAIC aircraft data}

Aircraft pressure, temperature and humidity data are provided by the MOZAIC database (http://mozaic.aero.obsmip.fr). Currently, the MOZAIC programme includes five aircrafts performing up to 2,500 flights per year. In this study data from March 6, 2001 until March 1, 2006 have been used. For water vapour, a special airborne humidity sensing device (AD-FS2), developed by Aerodata (Braunschweig, Germany) and based on the humidity and temperature transmitter HMP 230 of Vaisala (Helsinki, Finland), is used for measuring relative humidity and temperature of the atmosphere. For more details on MOZAIC humidity measurements see, e.g., [6]. MOZAIC measurement frequency is $0.25 \mathrm{~Hz}$ (raw data). For the profile data used in this study, raw data of the ascent and descent profiles are averaged on a fixed altitude grid of 85 layers, each extending over $150 \mathrm{~m}$. For cruise comparisons, averaged observations (averaging boxes of $150 \mathrm{~m}$ height and $60 \mathrm{sec}$ time duration) have been used.

\section{RESULTS}

\section{A. Profile comparison}

Applying a coincidence interval of three hours and $300 \mathrm{~km}$ in time and space respectively, 324 coinciding profiles from CHAMP and MOZAIC were found from March 2001 until March 2006. The corresponding vertical profile of compared data points representing the intersection of available CHAMP and MOZAIC data is given in Fig. 2(a). The global distribution of coincidences shown in Fig. 1(a) indicates the airport locations normally approached by the five MOZAIC aircrafts. Fig. 1(b) and (c) give an example of CHAMP (1DVAR and DWVP) specific humidity (b) and refractivity (c) vertical profiles in comparison to MOZAIC and ECMWF data. Here, both CHAMP humidity retrieval methods come to similar results revealing significant improvement over the ECMWF specific humidity in comparison to MOZAIC data. Whereas MOZAIC and ECMWF (used as ancillary data in occultation humidity retrieval) temperature profiles (not shown here) are in good agreement for this example, the MOZAIC refractivity shows better agreement with the CHAMP observation than with ECMWF, especially between 900 and $750 \mathrm{hPa}$ (Fig. 1(c)). This obviously corresponds to the better agreement between MOZAIC and CHAMP than between MOZAIC and ECMWF humidity profiles (Fig. 1(b)). Statistical comparisons of the MOZAIC, CHAMP and ECMWF vertical refractivity and specific humidity profiles are shown in Figs. 2 and 3. Here, solid lines represent bias and dashed lines standard deviation. The CHAMP RO refractivity shows a significant negative bias of up to $1.5 \%$ in the lower troposphere in comparison to MOZAIC (Fig. 2(c)). This bias is well known from comparisons to other meteorological data like radiosondes or ECMWF. With a small exception around 800 $\mathrm{hPa}$, the standard deviation between CHAMP and MOZAIC refractivity (from about $3.1 \%$ in the lower to $1 \%$ in the upper troposphere) is slightly larger than between ECMWF and MOZAIC (from about $2.9 \%$ to $0.7 \%$, Fig. 2(b)) through the entire altitude range. Nevertheless, the CHAMP-MOZAIC refractivity bias is smaller than the ECMWF-MOZAIC bias in the mid troposphere region between about 650 and $500 \mathrm{hPa}$. As Fig. 3(b) and (c) reveal, the statistical comparison of DWVP and IDVAR with MOZAIC humidity data comes to quite similar results. Only in the lower troposphere (below about $850 \mathrm{hPa}$ DWVP shows a slightly bigger negative CHAMPMOZAIC humidity bias (about $-0.7 \mathrm{~g} / \mathrm{kg}$ specific humidity) than 1DVAR (about $-0.5 \mathrm{~g} / \mathrm{kg}$ ). This is in argeement with validation studies with radiosonde data in [5]. Consistent with the refractivity comparisons shown in Fig. 2, the standard deviation between CHAMP (1DVAR, DWVP) and MOZAIC specific humidity (from about $1.3 \mathrm{~g} / \mathrm{kg}$ in the lower to 1 $\mathrm{g} / \mathrm{kg}$ in the mid troposphere) is slightly bigger than between ECMWF and MOZAIC (from about $1.1 \mathrm{~g} / \mathrm{kg}$ to $0.9 \mathrm{~g} / \mathrm{kg}$, Fig. 3(a)) through the entire altitude range. But concerning the humidity bias, Fig. 3 reveals better agreement of MOZAIC with CHAMP than with ECMWF between about 650 and $300 \mathrm{hPa}$. Keeping in mind that this comparison is carried out over continental regions where radiosonde data significantly contribute to the quality of meteorological analyses, this suggests that CHAMP data may provide additional humidity information in comparison to ECMWF at that altitude range.

\section{B. Cruise comparison}

During cruises at typically $10-11 \mathrm{~km}$ altitude humidity values range far below the accuracy which can be expected from RO humidity retrieval. Nevertheless, MOZAIC cruise measurements provide a valuable data source for validation of RO refractivity and temperature (retrieved assuming dry air conditions) results. To ensure validity of the dry air assumption, the cruise comparisons are restricted to altitudes above $300 \mathrm{hPa}$. In fact, about $95 \%$ of the data used in the following comparison have been measured in the altitude range between 300 and $200 \mathrm{hPa}$. About 3,500 coincidences (Fig. 4(a)) between CHAMP profiles and MOZAIC cruise data were found from March 2001 until March 2006 (coincidence radius: 3 hours, $300 \mathrm{~km}$ ). For the comparisons the data pairs along the coinciding cruises and profiles with the smallest spatial distance above $300 \mathrm{hPa}$ with less than three hours temporal distance have been used. Finally, about 2,700 data pairs fulfilled all selection criteria (including validity 
of MOZAIC measurements) and have been used in the statistical comparisons of refractivity (Fig. 5) and temperature (Fig. 6) between MOZAIC, CHAMP, and ECMWF. Since MOZAIC cruise data contain no other altitude information than pressure (or barometric altitude), CHAMP and ECMWF data are interpolated to MOZAIC pressure levels. In the upper troposphere and lower stratosphere region a negative bias of the CHAMP retrieval pressure is observed in comparison to ECMWF (about $-0.7 \mathrm{hPa}$ at $11 \mathrm{~km}$ altitude, Fig. 4(b)) for the selected coincidences (Fig. 4(a)). This can be explained by a small but widespread negative CHAMP refractivity bias in comparison to ECMWF starting from about $12 \mathrm{~km}$ altitude upwards (Fig. 4(c)). Assuming dry conditions, air density is directly proportional to refractivity. To derive occultation pressure the air density profile is integrated downward, gradually accumulating the small refractivity (density) bias to the observed pressure bias. This bias is consistent with geopotential height comparisons between GPS/MET occultations and ECMWF for latitudes greater than $30^{\circ} \mathrm{N}$ reported by [9]. Here a bias of about -15 geopotential meters (gpm) was shown for pressure levels around MOZAIC cruise altitude (a pressure bias of $-0.7 \mathrm{hPa}$ corresponds to about $-18 \mathrm{gpm}$ between 10 and $11 \mathrm{~km}$ altitude). For the comparisons shown in Figs. 5 and 6, ECMWF pressure is used to interpolate CHAMP refractivity and temperature data to MOZAIC pressure level. For this purpose ECMWF pressure is interpolated to CHAMP profile levels via ECMWF and CHAMP geopotential height. The comparison of MOZAIC refractivity above $300 \mathrm{hPa}$ (Fig. 5) with CHAMP and ECMWF reveal excellent agreement. Both, CHAMP and ECMWF show nearly no bias with respect to MOZAIC. Here, the application of the CHAMP retrieval pressure for altitude assignment of CHAMP data would result in a bias of $0.25 \%$ (0.21 N units) between CHAMP and MOZAIC. This gives also some evidence that the pressure bias between CHAMP and ECMWF is basically related to the CHAMP data. The MOZAIC refractivity comparison with CHAMP (about $1.1 \%$ standard deviation) reveals slightly more scattering than with ECMWF (about $0.9 \%$ ). Here, it has to be taken into account that temperature data of numerous airliners (e.g., Aircraft Communications, Addressing and Reporting System (ACARS) reports) are assimilated to ECMWF analyses along the main air lanes, contributing to a high ECMWF accuracy in these regions. Whereas MOZAIC temperature in comparison to ECMWF (Fig. 6(b)) shows nearly no bias above $300 \mathrm{hPa}$, CHAMP reveals a bias of $-0.87 \mathrm{~K}$ in comparison to MOZAIC. A similar negative bias is also known from validation studies with radiosonde data (e.g., [16]) and is obviously related to the negative bias of the CHAMP retrieval pressure (Fig. 4(b)) which is used subsequently in the CHAMP temperature retrieval. Applying Eq. 1 with the mean refractivity of about $87 \mathrm{~N}$ units for this comparison, a pressure bias of $-0.7 \mathrm{hPa}$ results in a temperature bias of $-0.62 \mathrm{~K}$. Similar to refractivity, the CHAMP temperature (about $2.3 \mathrm{~K}$ standard deviation) shows slightly more scattering in comparison to MOZAIC than ECMWF (about 2K).

\section{CONCLUSION}

MOZAIC atmospheric measurements provide a valuable data source for validation of GPS RO retrievals of refractivity, temperature and water vapor. According results are presented for the first time in this study. Comparisons of MOZAIC vertical refractivity and humidity profiles with CHAMP RO and ECMWF are in good agreement with former investigations concerning CHAMP, ECMWF and radiosonde data (e.g., [5]). Concerning the humidity bias, MOZAIC agrees better with CHAMP than with ECMWF between about 650 and $300 \mathrm{hPa}$. Since MOZAIC humidity data are not assimilated to ECMWF, this may reveal that CHAMP data provide, in comparison to ECMWF, additional humidity information in this altitude range. Comparisons of MOZAIC refractivity above $300 \mathrm{hPa}$ with CHAMP and ECMWF reveal excellent agreement. Here, CHAMP shows slightly more scattering in comparison to MOZAIC than ECMWF. Above $300 \mathrm{hPa}$, MOZAIC temperature shows nearly no bias in comparison to ECMWF, whereas CHAMP reveals a bias of about $-0.9 \mathrm{~K}$ in comparison to MOZAIC. This bias can be mostly explained by a bias in the CHAMP retrieval pressure which is used in the dry air temperature retrieval.

\section{ACKNOWLEDGMENT}

The authors acknowledge for their strong support the European Commission, Airbus and the Airlines (Lufthansa, Austrian, Air France) who carry free of charge the MOZAIC equipment and perform the maintenance since 1994. MOZAIC is supported by INSU-CNRS (Institut National des Sciences de l'Univers - Centre National de la Recherche Scientifique, France), Météo-France, and FZJ (Forschungszentrum Jülich, Germany). The authors are grateful to the CHAMP team for all efforts to provide this unique long term GPS RO data set. The German Weather Service provided ECMWF analysis data.

\section{REFERENCES}

[1] G. Beyerle, J. Wickert, T. Schmidt and C. Reigber, Atmospheric sounding by global navigation satellite system radio occultation: An analysis of the negative refractivity bias using CHAMP observations, J. Geophys. Res., 109, D01106, doi:10.1029/2003JD003922, 2004.

[2] G. Fjeldbo, A. J. Kliore and V. R. Eshleman, The neutral atmosphere of Venus as studied with the Mariner V radio occultation experiments, Astron. J., 76,2,123-140, 1971.

[3] S. B. Healy and J. R. Eyre, Retrieving temperature, water vapour and surface pressure information from refractive-index profiles derived by radio occultation data: A simulation study, Q. J. R. Meteorol. Soc., 126, $1661-1683,2000$

[4] S. B. Healy, J. Wickert, G. Michalak, T. Schmidt and G. Beyerle, Combined forecast impact of GRACE-A and CHAMP GPS radio occultation bending angle profiles, Atmos. Sci. Let., 8, 43-50, 2007.

[5] S. Heise, J. Wickert, G. Beyerle, T. Schmidt and C. Reigber, Global monitoring of tropospheric water vapor with GPS radio occutation aboard CHAMP, Adv. Space Research, 37, 2222-2227, 2006.

[6] M. Helten, H. G. J. Smit, W. Sträter, D. Kley, P. Nedelec, M. Zöger and R. Busen, Calibration and performance of automatic compact instrumentation for the measurement of relative humidity from passenger aircraft, J. Geophys. Res., 103, 25,643-25,652, 1998.

[7] A. S. Jensen, M. Lohmann, H. H. Benzon and A. Nielsen, Full Spectrum inversion of radio occultation signals, Radio Sci., 38(3), doi:10.1029/2002RS002763, 2003.

[8] E. R. Kursinski, G. A. Hajj, K. R. Hardy, J. T. Schofield and R. Linfield, Observing Earth's atmosphere with radio occultation measurements using the Global Positioning System, J. Geophys. Res., 102, 23429-23465, 1997. 
[9] S. S. Leroy, Measurement of geopotential heights by GPS radio occultation, J. Geophys. Res., 102, D6, 6971-6986, 1997.

[10] M. Loiselet, N. Stricker, Y. Menard, and J.-P. Luntama, GRAS - Metop's GPS-based atmospheric sounder, ESA Bulletin, 102, 38-44, 2000.

[11] W. G. Melbourne, E. S. Davis, G. A. Hajj, K. R. Hardy, E. R. Kursinski, T. K. Meehan and L. E. Young, The application of spaceborne GPS to atmospheric limb sounding and global change monitoring, JPL Publication, 94-18, Jet Propulsion Laboratory, Pasadena, California, 1994.

[12] C. Reigber, H. Lühr, P. Schwintzer and J. Wickert (Eds.), Earth Observation with CHAMP - Results from Three Years in Orbit, Springer, Berlin, Heidelberg, New York, ISBN 3-540-22804-7, 2005.

[13] W. Schreiner, C. Rocken, S. Sokolovskiy, S. Syndergaard and D. Hunt, Estimates of the precision of GPS radio occultations from COSMIC/FORMOSAT-3 mission, Geophys. Res. Lett., 34, L04808, doi:10.1029/2006GL027557, 2007.

[14] J. Wickert, T. Schmidt, G. Beyerle, R. König, C. Reigber and N. Jakowski, The radio occultation experiment aboard CHAMP: Operational data analysis and validation of atmospheric profiles, J. Meteorol. Soc. Japan, 82(1B), 381-395, 2004.

[15] J. Wickert, T. Schmidt, G. Beyerle, G. Michalak, R. König, S. Heise and C. Reigber, GPS radio occultation with CHAMP and GRACE: Recent results, in: Atmosphere and Climate: Studies by Occultation Methods, U. Foelsche, G. Kirchengast, A. Steiner (Eds.), ISBN 3-540-34116-1, Springer, Berlin, Heidelberg, New York, 3-16, 2006.

[16] J. Wickert, G. Michalak, T. Schmidt, G. Beyerle, C. Z. Cheng, S. B. Healy, S. Heise, C. Y. Huang, N. Jakowski, W. Köhler, C. Mayer, D. Offiler, E. Ozawa, A. G. Pavelyev, M. Rothacher, B. Tapley and Ch. Viehweg, GPS radio occultation: Results from CHAMP, GRACE and FORMOSAT-3/COSMIC, Terrestrial, Atmospheric and Oceanic Sciences (TAO), in print, 2008.

[17] T. P. Yunck, C. H. Liu and R. Ware, A history of GPS sounding, Terr. Atmos. and Oceanic Sci., 11(1), 1-20, 2000. 

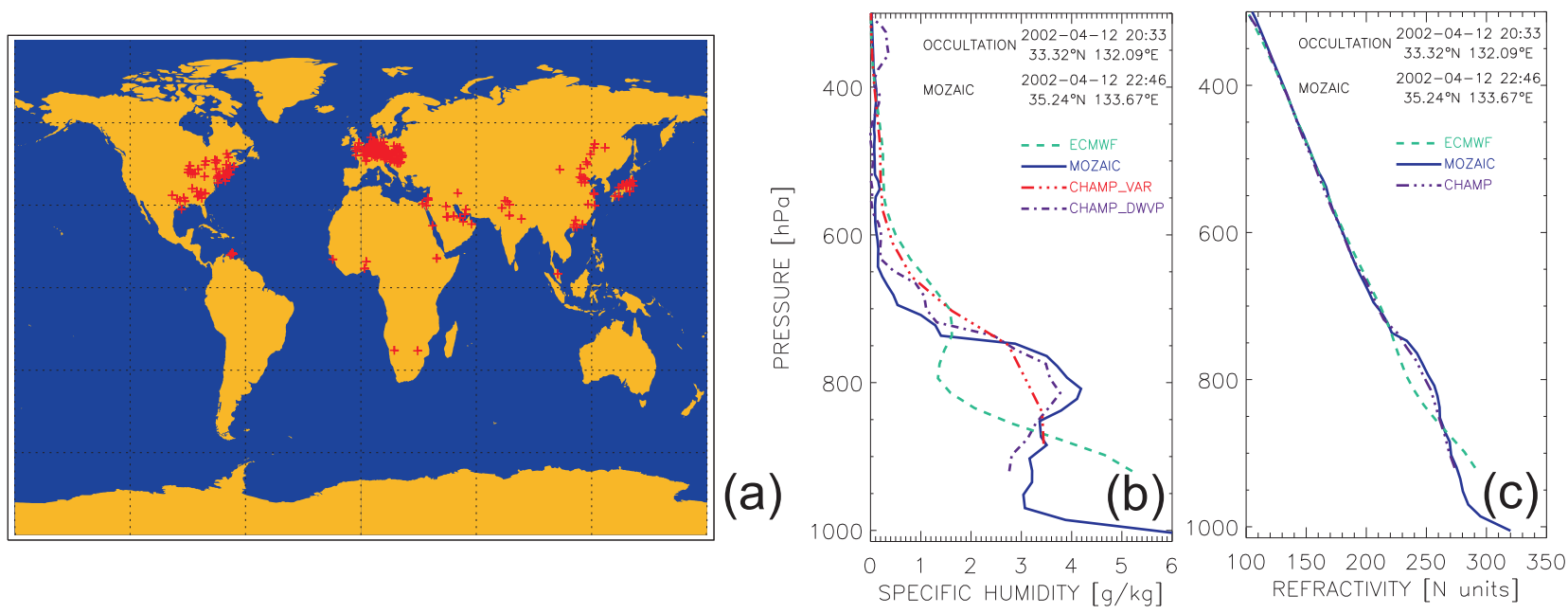

Fig. 1. (a) Coincidences of CHAMP and MOZAIC vertical profiles from March 2001 until March 2006 (coincidence radius: 3 h, 300 km). Comparison of vertical specific humidity (b) and refractivity (c) profiles derived from CHAMP (1DVAR and DWVP) retrieval with MOZAIC and ECMWF data. Example for April 12, 2002, 20:33 UTC, $33.32^{\circ} \mathrm{N}, 132.09^{\circ} \mathrm{E}$.
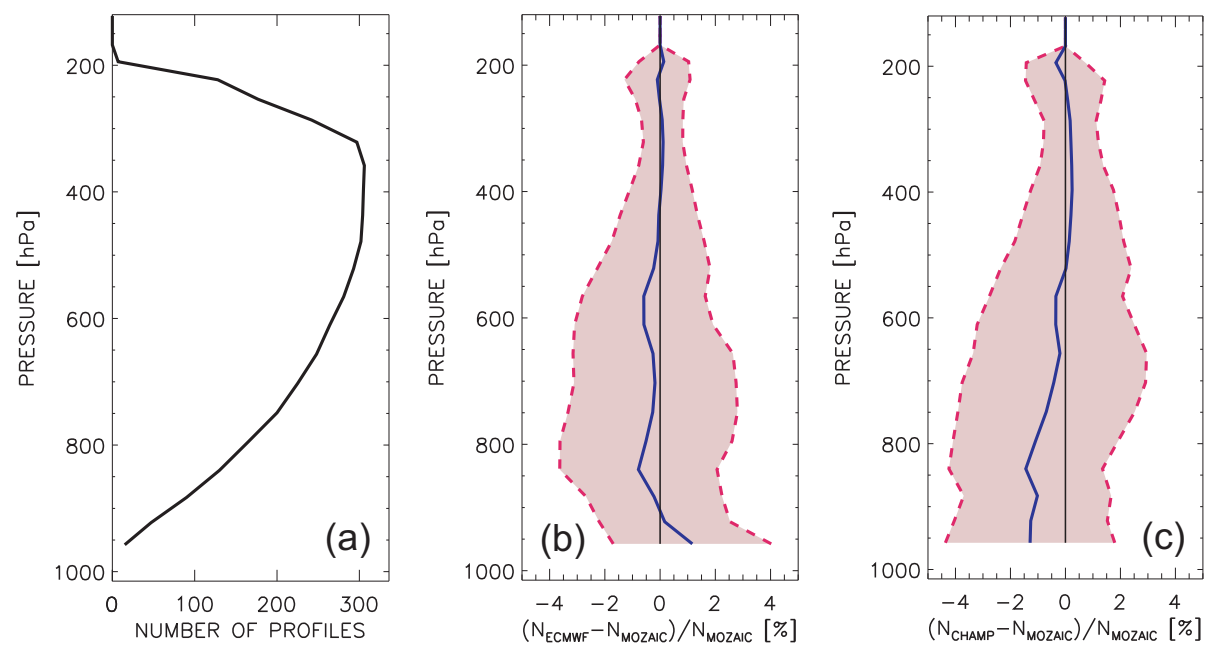

Fig. 2. (a) Number of profiles corresponding to (b), (c), and Fig. 3. Statistical comparison of vertical refractivity profiles from MOZAIC with: (b) ECMWF, and (c) CHAMP. Solid line represents bias, dashed lines standard deviation.
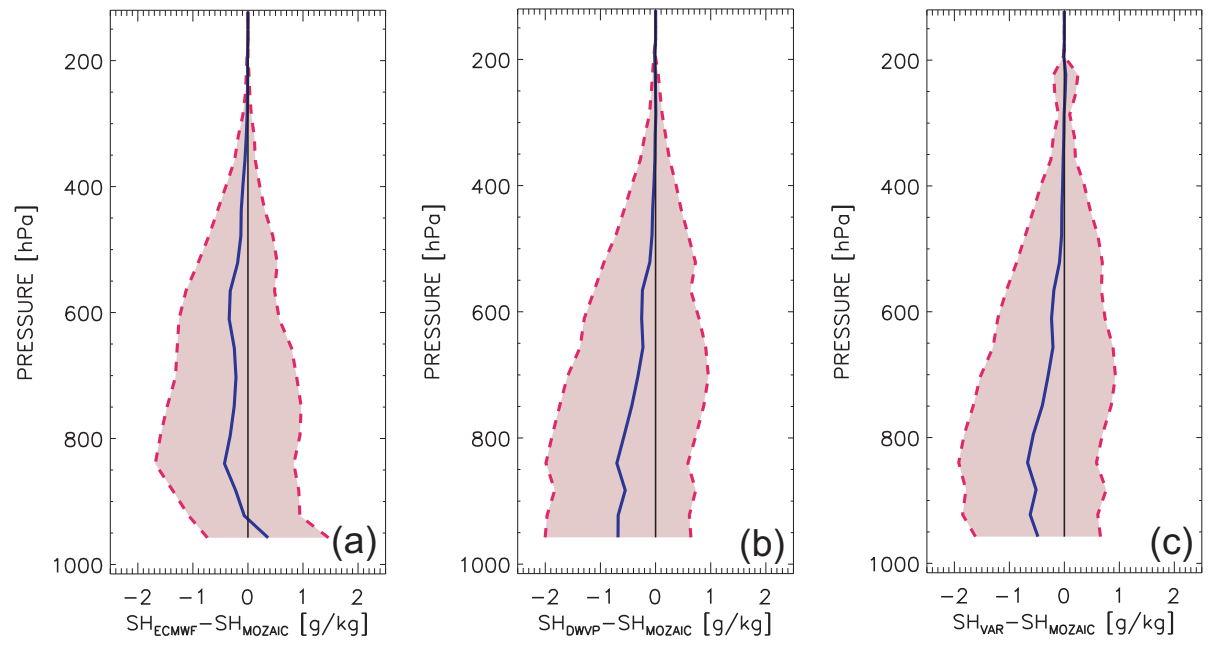

Fig. 3. Statistical comparison of vertical specific humidity profiles from MOZAIC with: (a) ECMWF, (b) CHAMP-DWVP, and (c) CHAMP-1DVAR. 

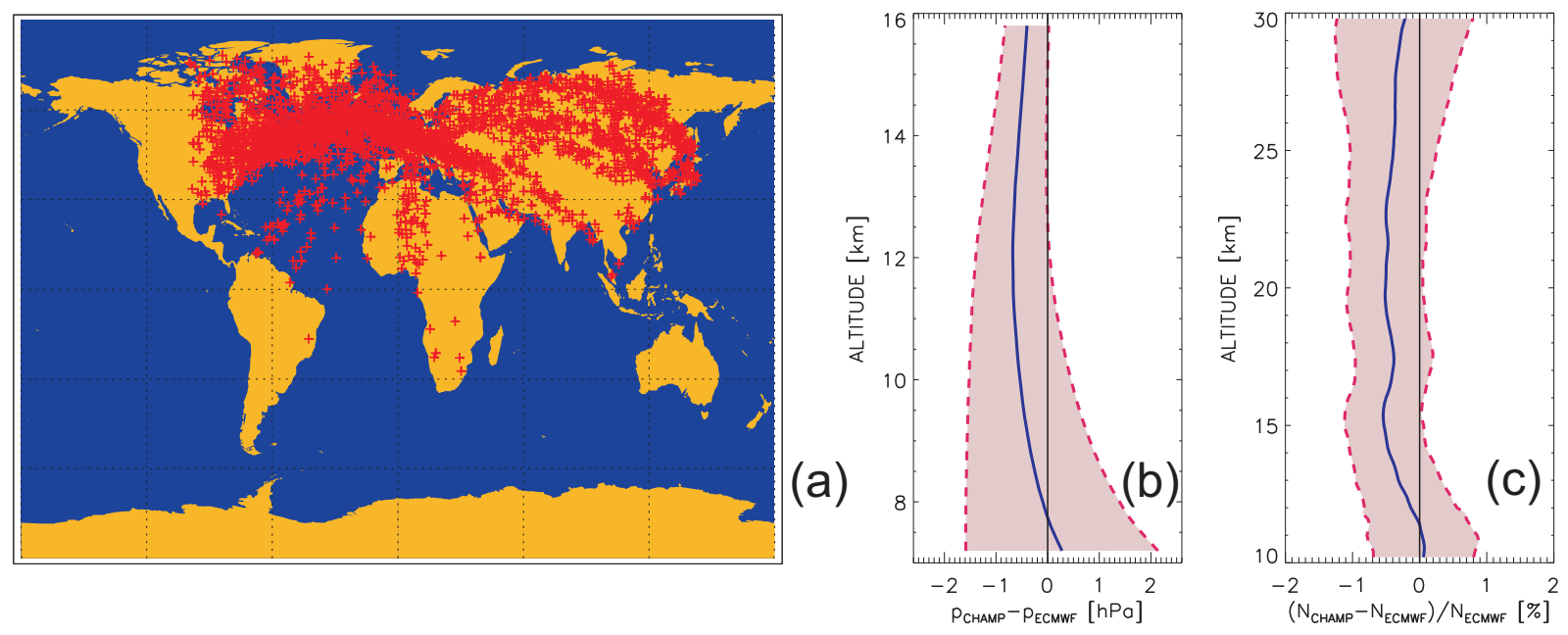

Fig. 4. (a) Coincidences of CHAMP vertical profiles and MOZAIC cruise data from March 2001 until March 2006 corresponding to (b), (c), Fig. 5, and Fig. 6. Comparison of vertical pressure (b) and refractivity (c) profiles from CHAMP and ECMWF, solid line represents bias, dashed lines standard deviation. Ordinate is altitude above mean sea level, ECMWF data are interpolated via geopotential height to CHAMP altitude levels.
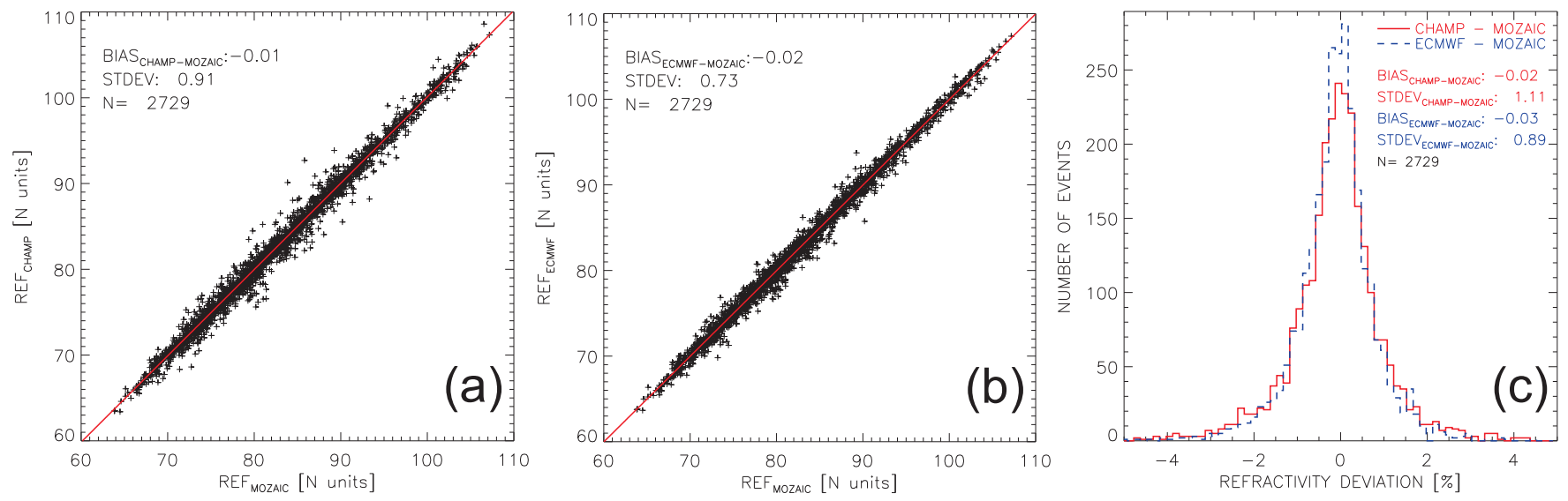

Fig. 5. Comparison of refractivity data from MOZAIC above $300 \mathrm{hPa}$ with (a) CHAMP, (b) ECMWF, (c) CHAMP and ECMWF.
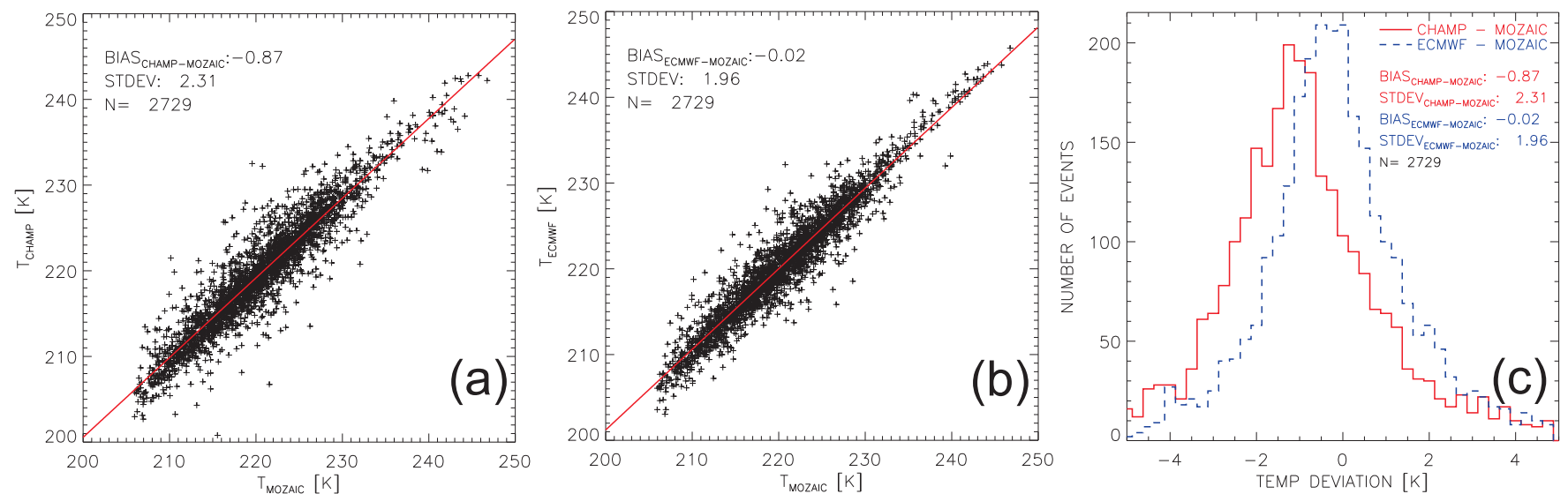

Fig. 6. Comparison of temperature data from MOZAIC above $300 \mathrm{hPa}$ with (a) CHAMP, (b) ECMWF, (c) CHAMP and ECMWF. 